\title{
Sinefungin VA and dehydrosinefungin V, new antitrypanosomal antibiotics produced by Streptomyces sp. K05-0178
}

\author{
Megumi Niitsuma $^{1}$, Junko Hashida ${ }^{1}$, Masato Iwatsuki ${ }^{1}$, Mihoko Mori ${ }^{2}$, Aki Ishiyama ${ }^{1}$, Miyuki Namatame ${ }^{1}$, \\ Aki Nishihara-Tsukashima ${ }^{1}$, Atsuko Matsumoto ${ }^{2}$, Yoko Takahashi ${ }^{2}$, Haruki Yamada ${ }^{2}$, Kazuhiko Otoguro ${ }^{1}$, \\ Kazuro Shiomi ${ }^{2}$ and Satoshi Ōmura ${ }^{2}$
}

Two new nucleotide antibiotics, named sinefungin VA and dehydrosinefungin $\mathrm{V}$, were separated by cation exchange column chromatography and purified by HPLC from the culture broth of Streptomyces sp. K05-0178, together with the known antibiotics, sinefungin, dehydrosinefungin and KSA-9342. The structures of the two novel sinefungin analogs were elucidated by spectroscopic studies, including various NMR and advanced peptide chemical methods. Sinefungin VA consists of adenosine and ornithylvalylalanine, whereas dehydrosinefungin V consists of $4^{\prime}, 5^{\prime}$-dehydroadenosine and ornithylvaline. Sinefungin VA showed potent antitrypanosomal activity with an $\mathrm{IC}_{50}$ value of $0.0026 \mu \mathrm{g} \mathrm{ml}^{-1}$ in vitro without cytotoxicity against MRC-5 cells. Dehydrosinefungin $\mathrm{V}$ showed moderate antitrypanosomal activity $\left(\mathrm{IC}_{50}=0.15 \mu \mathrm{g} \mathrm{ml}^{-1}\right)$.

The Journal of Antibiotics (2010) 63, 673-679; doi:10.1038/ja.2010.102; published online 22 September 2010

Keywords: antitrypanosomal antibiotics; dehydrosinefungin V; sinefungin VA; Streptomyces

\section{INTRODUCTION}

Human African trypanosomiasis, also known as sleeping sickness, is regarded as one of the major neglected tropical diseases. It is a complex disease caused by infection with protozoan Trypanosoma spp. parasites, transmitted through the bites of infected tsetse flies. There are two forms of the disease, each having two distinct stages, and without treatment the disease is fatal. Today, some 70 million people are exposed to the threat of human African trypanosomiasis. ${ }^{1}$ It was estimated that, in 2004, approximately 50 000-70 000 new cases of human African trypanosomiasis were occurring annually. ${ }^{1}$ Currently, only four drugs, pentamidine, suramin, melarsoprol and eflornithine, are registered for the treatment of human African trypanosomiasis. All four are unsatisfactory, as they cannot be administered orally and are hampered by severe toxicity and increasing resistance of the parasites. Although there is a clear and urgent need for new classes of antitrypanosomal compounds, and despite the recent introduction of a new treatment using a combination of two existing drugs, no effective new drugs have been introduced into the field for 20 years.

During our screening program to discover new antitrypanosomal antibiotics, two novel sinefungin analogs, sinefungin VA (1) and dehydrosinefungin $\mathrm{V}(2)$, and three recognized structurally related compounds, sinefungin (3), dehydrosinefungin (4) and KSA-9342 (5), were isolated from a culture broth of Streptomyces sp. K05-0178 (Figure 1). In this paper, the fermentation, isolation, physicochemical properties and structure elucidation and biological properties of $\mathbf{1}$ and 2 are described.

\section{RESULTS}

Taxonomy of the producing strain K05-0178

The strain K05-0178 was isolated from a soil sample collected at Minato-ku, Tokyo, Japan. The vegetative mycelia developed well on yeast extract-malt extract agar, oatmeal agar and inorganic saltsstarch agar and did not show fragmentation into coccoid forms or bacillary elements. The color of vegetative mycelia showed red. Aerial mycelia were produced abundantly on inorganic salts-starch agar and the aerial mass color showed pink. The strain formed verticillate sporophores bearing terminal umbels of spore chains (Figure 2). The mature spore chain had 5-10 spores per chain. The spores were cylindrical in shape, $1.0 \times 0.5 \mu \mathrm{m}$ in size and had a smooth surface. Brownish soluble pigment was produced on yeast extract-malt extract agar. The isomer of diaminopimelic acid in whole-cell hydrolysates of strain K05-0178 was determined to be the LL-form. An almost complete $16 \mathrm{~S}$ rDNA sequence (1400 nucleotides) was determined, and the result of the identification analysis by EzTaxon.org server version 2.1 (http://147.47.212.35:8080/) showed the highest similarity

\footnotetext{
${ }^{1}$ Research Center for Tropical Diseases, Kitasato Institute for Life Sciences, Kitasato University, Tokyo, Japan and ${ }^{2}$ Kitasato Institute for Life Sciences and Graduate School of Infection Control Sciences, Kitasato University, Tokyo, Japan

Correspondence: Professor K Shiomi or Professor S Ōmura, Kitasato Institute for Life Sciences and Graduate School of Infection Control Sciences, Kitasato University, 5-9-1 Shirokane, Minato-ku, Tokyo 108-8641, Japan.

E-mail: shiomi@lisci.kitasato-u.ac.jp or omuras@insti.kitasato-u.ac.jp

Received 26 April 2010; revised 23 July 2010; accepted 12 August 2010; published online 22 September 2010
} 


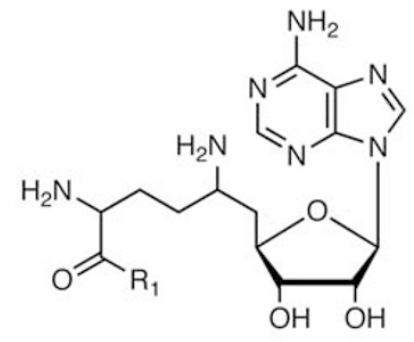

\begin{tabular}{lc}
\hline & $\mathrm{R}_{1}$ \\
\hline Sinefungin VA (1) & L-Val-L-Ala \\
Sinefungin (3) & $\mathrm{OH}$ \\
\hline
\end{tabular}<smiles></smiles>

\begin{tabular}{lc}
\hline & $\mathrm{R}_{2}$ \\
\hline Dehydrosinefungin V (2) & L-Val \\
Dehydrosinefungin (4) & $\mathrm{OH}$ \\
KSA-9342 (5) & L-Val-L-Ala \\
\hline
\end{tabular}

Figure 1 Structures of sinefungin VA (1), dehydrosinefungin V (2), sinefungin (3), dehydrosinefungin (4) and KSA-9342 (5).

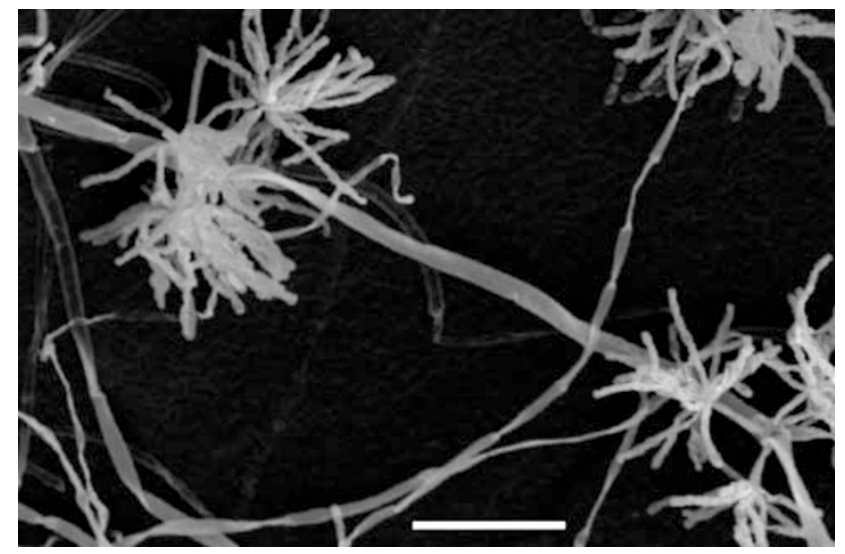

Figure 2 Scanning electron micrograph of the strain K05-0178 grown on $1 / 10 \mathrm{~V}-8$ juice agar at $27^{\circ} \mathrm{C}$ for 18 days. Bar represents $10 \mu \mathrm{m}$.

value with Streptomyces coerulescens NBRC $12758^{\mathrm{T}}$ (AB184122, 99.6\%) and Streptomyces abikoensis NBRC $13860^{\mathrm{T}}$ (AB184537, 99.6\%). On the basis of the morphological and cultural properties and 16S rDNA sequence similarity, the strain was identified with whorl-forming Streptomyces species and designated Streptomyces sp. K05-0178.,3

\section{Isolation}

The procedure for isolation of sinefungin analogs is summarized in Scheme 1. The 6-day-old culture broth (101) was extracted with 101 of ethanol and filtered through a paper to separate into supernatant and mycelia. The supernatant was concentrated under reduced pressure to remove ethanol and then passed through a Dowex $50 \mathrm{~W} \times 2\left[\mathrm{H}^{+}\right]$ column (50 i.d. $\times 400 \mathrm{~mm}$, Dow Chemical, Midland, MI, USA) previously activated. After washing with water $(600 \mathrm{ml})$, the active materials were eluted with $1.0 \mathrm{M} \mathrm{NH} \mathrm{NH}_{4} \mathrm{OH}(600 \mathrm{ml})$, followed by neutralization by $\mathrm{HCl}$ and desalted by a Micro Acylizer S3 (ASTOM, Tokyo, Japan). The whole eluate was applied on a Toyopearl SP-650C column (3.0 i.d. $\times 300 \mathrm{~mm}$, Tosoh Co., Tokyo, Japan) previously equilibrated with $0.1 \mathrm{M} \mathrm{CH}_{3} \mathrm{COONH}_{4}$ buffer ( $\mathrm{pH} 3.8$ ).

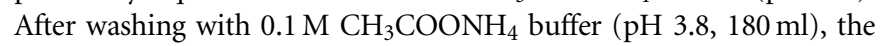
active materials were eluted with $0.2,0.4$ and $0.6 \mathrm{M} \mathrm{CH}_{3} \mathrm{COONH}_{4}$ buffers ( $\mathrm{pH} 3.8,180 \mathrm{ml}$ each). The 0.4 and $0.6 \mathrm{M} \mathrm{CH}_{3} \mathrm{COONH}_{4}$ fractions were neutralized by $\mathrm{NH}_{4} \mathrm{OH}$, desalted by the Micro Acylizer and concentrated in vacuo to dryness to yield a brown material $(1143 \mathrm{mg})$. The material was dissolved in a small amount of water and purified by HPLC on an XBridge Shield RP18 column (10 i.d. $\times 250 \mathrm{~mm}$, Waters Milford, MA, USA) with $1.5 \% \mathrm{CH}_{3} \mathrm{CN} / 10 \mathrm{~mm}$ $\mathrm{CH}_{3} \mathrm{COONH}_{4}(\mathrm{pH} \mathrm{10})$ at $4.0 \mathrm{ml} \mathrm{min}^{-1}$ detected at $\mathrm{UV} 210 \mathrm{~nm}$. The retention times of sinefungin VA (1), dehydrosinefungin $\mathrm{V}$ (2) and KSA-9342 (5) were 33, 42 and 55 min, respectively (Figure 3a). Each solution was neutralized by $\mathrm{HCl}$, desalted by Sephadex G-10 (GE Healthcare, Buckinghamshire, UK) gel filtration chromatography and concentrated in vacuo to dryness to afford $\mathbf{1}(0.2 \mathrm{mg}), 2(29 \mathrm{mg})$ and 5 ( $49 \mathrm{mg}$ ) as pale brown powders. On the other hand, the $0.2 \mathrm{M}$ $\mathrm{CH}_{3} \mathrm{COONH}_{4}$ fraction was neutralized, desalted by the Micro Acylizer and concentrated in vacuo to dryness to yield a brown material $(438 \mathrm{mg})$. It was dissolved in a small amount of water and purified by HPLC on an XBridge Shield RP18 column (10 i.d. $\times 250 \mathrm{~mm}$ ) with $0.5 \% \mathrm{CH}_{3} \mathrm{CN} / 10 \mathrm{~mm} \mathrm{CH}_{3} \mathrm{COONH}_{4}(\mathrm{pH} 10)$ at $4.0 \mathrm{ml} \mathrm{min}^{-1}$ detected at UV $210 \mathrm{~nm}$. The retention times of sinefungin (3) and dehydrosinefungin (4) were 9 and $13 \mathrm{~min}$, respectively (Figure 3b). Each solution was neutralized by $\mathrm{HCl}$, desalted by the Micro Acylizer and concentrated in vacuo to dryness to afford $3(73 \mathrm{mg})$ and $4(60 \mathrm{mg})$ as pale brown powders.

\section{Physicochemical properties}

The physicochemical properties of sinefungin VA (1) and dehydrosinefungin $\mathrm{V}(2)$ are summarized in Table 1 . They are both readily soluble in water, methanol and acetone. They showed absorption maxima at 206 and $260 \mathrm{~nm}$ in UV spectra. The broad IR absorption at $3300 \mathrm{~cm}^{-1}$ suggested the presence of hydroxyl groups. The similarity in physicochemical properties strongly suggested that they are structurally related to sinefungin (3).

Identification of sinefungins, dehydrosinefungin and KSA-9342 The molecular formulae of $\mathbf{3}-\mathbf{5}$ were elucidated by HR-FAB-MS to be $\mathrm{C}_{15} \mathrm{H}_{23} \mathrm{~N}_{7} \mathrm{O}_{5}, \mathrm{C}_{15} \mathrm{H}_{21} \mathrm{~N}_{7} \mathrm{O}_{5}$ and $\mathrm{C}_{23} \mathrm{H}_{35} \mathrm{~N}_{9} \mathrm{O}_{7}$, respectively (Table 1). The analysis of ${ }^{1} \mathrm{H},{ }^{13} \mathrm{C}$ and $2 \mathrm{D}$ NMR spectra data led to the identification of $\mathbf{3 - 5}$ as sinefungin, ${ }^{4}$ dehydrosinefungin ${ }^{5}$ and KSA9342, ${ }^{6}$ respectively. As the assignments of their chemical shifts have not been reported, the data are shown in Table 2. 


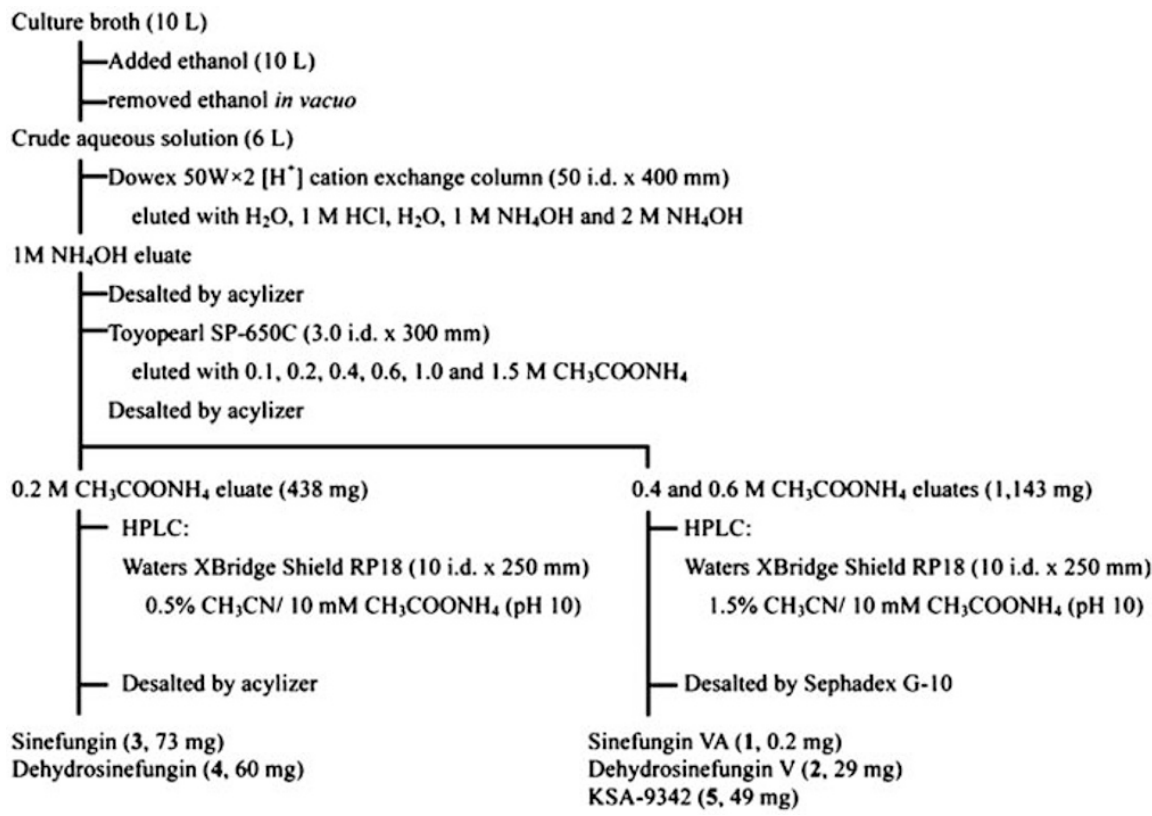

Scheme 1 Purification of sinefungin analogs.
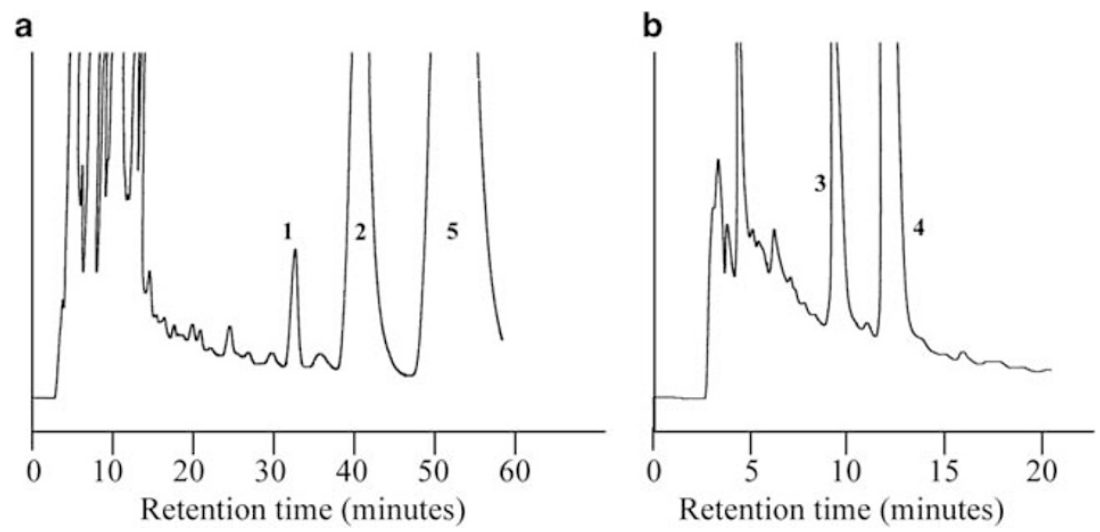

Figure 3 Chromatographic profile of (a) sinefungin VA (1), dehydrosinefungin V (2) and KSA-9342 (5) and (b) sinefungin (3) and dehydrosinefungin (4) by preparative HPLC.

\section{Structure elucidation of sinefungin VA (1)}

The molecular formula of $\mathbf{1}$ was elucidated by HR-FAB-MS to be $\mathrm{C}_{23} \mathrm{H}_{37} \mathrm{~N}_{9} \mathrm{O}_{7}$, requiring 10 degrees of unsaturation. The ${ }^{1} \mathrm{H}$ and ${ }^{13} \mathrm{C}$ NMR spectral data of $\mathbf{1}$ are listed in Table 2 . The ${ }^{13} \mathrm{C}$ NMR and heteronuclear multiple quantum coherence (HMQC) spectra indicated 23 carbons, which were classified into one carboxyl carbon at $\delta_{c}$ 181.3 , two amide carbonyl carbons, five olefinic carbons, one hemiaminal carbon at $\delta_{\mathrm{c}} 88.8$, three oxygenated $s p^{3}$ methine carbons, four nitrogenated $s p^{3}$ methine carbons, one $s p^{3}$ methine carbon, three $s p^{3}$ methylene carbons and three methyl carbons. The characteristic UV spectra and fragment ion $(\mathrm{m} / \mathrm{z} 135)$ in FAB-MS indicated the presence of an adenine moiety. Moreover, the spin systems from $\mathrm{H}-2$ to $\mathrm{H}-10$, deduced by the COSY, and the correlations from $\mathrm{H}-2$ to $\mathrm{C}-1$ and $\mathrm{C}-3$, from $\mathrm{H}-5$ to $\mathrm{C}-7$, from $\mathrm{H}-8$ and $\mathrm{H}-9$ to $\mathrm{C}-10$, and from $\mathrm{H}-10$ to $\mathrm{C}-11$ and $\mathrm{C}-15$ of the adenine moiety in the heteronuclear multiple-bond correlation (HMBC) spectra, revealed 1 was a sinefungin analog (Figure 4). This was confirmed by comparison with the NMR spectra of sinefungin (Table 2). The spin systems from $\mathrm{H}-2^{\prime}$ to $\mathrm{H}_{3}-5^{\prime}$ and from $\mathrm{H}-2^{\prime \prime}$ to $\mathrm{H}_{3}-3^{\prime \prime}$ by the COSY and the correlations from $\mathrm{H}-2^{\prime}$ and $\mathrm{H}-2^{\prime \prime}$ to $\mathrm{C}-1^{\prime}$ and from $\mathrm{H}_{3}-3^{\prime \prime}$ to $\mathrm{C}-1^{\prime \prime}$ in the HMBC spectra indicated the presence of the valylalanine moiety. The correlations from $\mathrm{H}-2^{\prime}$ to $\mathrm{C}-1$ in $\mathrm{HMBC}$ revealed the $\mathrm{C}-1$ of the sinefungin moiety was attached to the amino group of valylalanyl moiety, to form an amide bond. This was confirmed by fragment ions of $m / z 463[\mathrm{M}-\mathrm{Ala}+\mathrm{H}]^{+}$and $m / z 346$ $[\mathrm{M}-\mathrm{Val}-\mathrm{Ala}+\mathrm{H}]^{+}$. The absolute configurations of amino acid residues of 1 were elucidated to be L-Val and L-Ala by HPLC analysis of the hydrolysates of 1 using a chiral column. Thus, the structure of 1 is shown in Figure 1, and the compound was designated as sinefungin VA.

Structure elucidation of dehydrosinefungin V (2)

The molecular formula of 2 was elucidated by HR-FAB-MS to be $\mathrm{C}_{20} \mathrm{H}_{30} \mathrm{~N}_{8} \mathrm{O}_{6}$, requiring 10 degrees of unsaturation. The ${ }^{1} \mathrm{H}$ and ${ }^{13} \mathrm{C}$ NMR spectral data of 2 are listed in Table 2 . The ${ }^{13} \mathrm{C}$ NMR and HMQC spectra indicated 20 carbons, which were classified into one carboxyl carbon at $\delta_{c} 178.4$, one amide carbonyl carbon at $\delta_{c} 169.1$, seven olefinic carbons containing one oxygenated olefinic carbon at $\delta_{\mathrm{c}}$ 159.9 , one hemiaminal carbon at $\delta_{\mathrm{c}} 87.9$, two oxygenated $s p^{3}$ methine carbons, three nitrogenated $s p^{3}$ methine carbons, one $s p^{3}$ methine carbon, two $s p^{3}$ methylene carbons and two methyl carbons. The 
Table 1 Physicochemical properties of sinefungin analogs

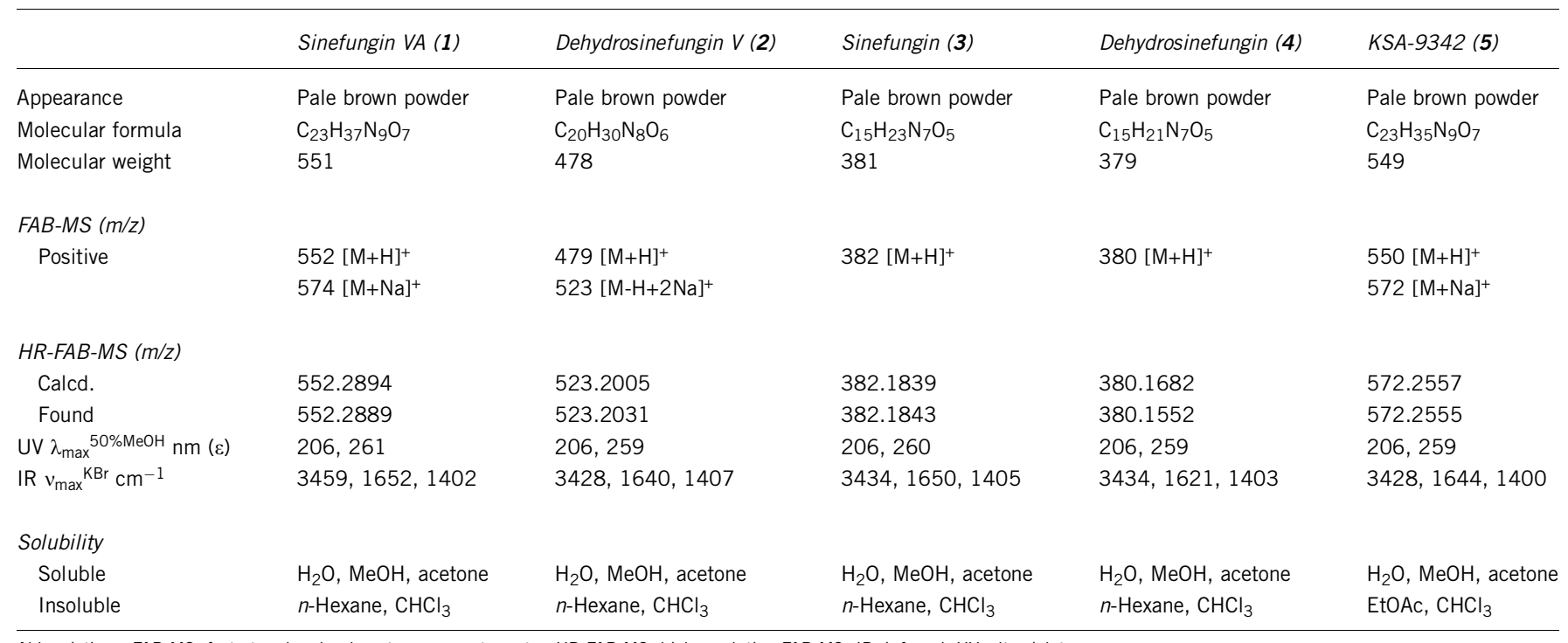

Abbreviations: FAB-MS, fast atom bombardment mass spectrometry; HR-FAB-MS, high-resolution FAB-MS; IR, infrared; UV, ultraviolet.

Table $2{ }^{1} \mathrm{H}$ and ${ }^{13} \mathrm{C}$ nuclear magnetic resonance spectral date of sinefungin analogs

\begin{tabular}{|c|c|c|c|c|c|c|c|c|c|c|}
\hline \multirow[b]{2}{*}{ Position } & \multicolumn{2}{|r|}{ Sinefungin VA (1) } & \multicolumn{2}{|c|}{ Dehydrosinefungin V(2) } & \multicolumn{2}{|r|}{ Sinefungin (3) } & \multicolumn{2}{|r|}{ Dehydrosinefungin (4) } & \multicolumn{2}{|r|}{ KSA-9342 (5) } \\
\hline & ${ }^{13} \mathrm{C}$ & ${ }^{1} \mathrm{H}(\mathrm{J}$ in $\mathrm{Hz})$ & ${ }^{13} \mathrm{C}$ & ${ }^{1} \mathrm{H}(\mathrm{J}$ in $\mathrm{Hz})$ & ${ }^{13} \mathrm{C}$ & ${ }^{1} \mathrm{H}(\mathrm{J}$ in $\mathrm{Hz})$ & ${ }^{13} \mathrm{C}$ & ${ }^{1} H(J$ in $H z)$ & ${ }^{13} \mathrm{C}$ & ${ }^{1} \mathrm{H}(\mathrm{J}$ in $\mathrm{Hz})$ \\
\hline 1 & 169.7 & - & 169.1 & - & 173.8 & - & 174.0 & - & 171.0 & - \\
\hline 2 & 52.7 & $4.17(1 \mathrm{H}, \mathrm{m})$ & 52.5 & $4.03(1 \mathrm{H}, \mathrm{m})$ & 53.8 & $3.62(1 \mathrm{H}, \mathrm{t}, 7.0)$ & 53.9 & $3.80(1 \mathrm{H}, \mathrm{t}, 7.0)$ & 52.7 & $4.02(1 \mathrm{H}, \mathrm{m})$ \\
\hline \multirow[t]{2}{*}{3} & 27.3 & $1.38(1 \mathrm{H}, \mathrm{m})$ & 27.6 & $1.17(1 \mathrm{H}, \mathrm{m})$ & 22.8 & $1.80(2 \mathrm{H}, \mathrm{m})$ & 26.8 & $1.88(1 \mathrm{H}, \mathrm{m})$ & 28.0 & $1.22(1 \mathrm{H}, \mathrm{m})$ \\
\hline & & $1.82(1 \mathrm{H}, \mathrm{m})$ & & $1.77(1 \mathrm{H}, \mathrm{m})$ & & & & $1.92(1 \mathrm{H}, \mathrm{m})$ & & $1.84(1 \mathrm{H}, \mathrm{m})$ \\
\hline \multirow[t]{2}{*}{4} & 28.2 & $1.40(1 \mathrm{H}, \mathrm{m})$ & 28.2 & $1.61(1 \mathrm{H}, \mathrm{m})$ & 26.5 & $1.70(1 \mathrm{H}, \mathrm{m})$ & 28.7 & $1.90(1 \mathrm{H}, \mathrm{m})$ & 29.0 & $1.65(1 \mathrm{H}, \mathrm{m})$ \\
\hline & & $1.84(1 \mathrm{H}, \mathrm{m})$ & & $1.79(1 \mathrm{H}, \mathrm{m})$ & & $1.90(1 \mathrm{H}, \mathrm{m})$ & & $1.95(1 \mathrm{H}, \mathrm{m})$ & & $1.86(1 \mathrm{H}, \mathrm{m})$ \\
\hline 5 & 49.0 & $3.58(1 \mathrm{H}, \mathrm{m})$ & 48.6 & $4.10(1 \mathrm{H}, \mathrm{m})$ & 48.8 & $3.41(1 \mathrm{H}, \mathrm{m})$ & 48.5 & $4.20(1 \mathrm{H}, \mathrm{m})$ & 48.5 & $4.12(1 \mathrm{H}, \mathrm{m})$ \\
\hline 6 & 34.2 & $2.20(2 \mathrm{H}, \mathrm{m})$ & 99.5 & $4.92(1 \mathrm{H}, \mathrm{d}, 3.1)$ & 34.0 & $2.06(2 \mathrm{H}, \mathrm{m})$ & 99.5 & $5.05(1 \mathrm{H}, \mathrm{m})$ & 99.5 & $4.80(1 \mathrm{H}, \mathrm{m})$ \\
\hline 7 & 73.3 & $4.35(1 \mathrm{H}, \mathrm{dt}, 7.2,7.1)$ & 159.9 & - & 72.5 & $4.15(1 \mathrm{H}, \mathrm{dt}, 6.2,6.0)$ & 159.6 & - & 160.5 & - \\
\hline 8 & 80.0 & $4.27(1 \mathrm{H}, \mathrm{m})$ & 67.4 & $4.94(1 \mathrm{H}, \mathrm{d}, 3.1)$ & 79.5 & $4.20(1 \mathrm{H}, \mathrm{dd}, 6.2,6.2)$ & 67.2 & $5.10(1 \mathrm{H}, \mathrm{d}, 6.2)$ & 67.3 & $4.67(1 \mathrm{H}, \mathrm{m})$ \\
\hline 9 & 73.2 & $4.80(1 \mathrm{H}, \mathrm{dd}, 7.3,6.2)$ & 72.5 & $4.89(1 \mathrm{H}, \mathrm{m})$ & 72.3 & $4.60(1 \mathrm{H}, \mathrm{dd}, 7.0,6.2)$ & 72.3 & $5.00(1 \mathrm{H}, \mathrm{dd}, 7.0,6.2)$ & 72.4 & $4.99(1 \mathrm{H}, \mathrm{dd}, 7.5,6.2)$ \\
\hline 10 & 88.8 & $6.05(1 \mathrm{H}, \mathrm{d}, 7.3)$ & 87.9 & $6.20(1 \mathrm{H}, \mathrm{d}, 7.3)$ & 88.5 & $5.88(1 \mathrm{H}, \mathrm{d}, 7.0)$ & 87.8 & $6.23(1 \mathrm{H}, \mathrm{d}, 7.0)$ & 88.0 & $6.17(1 \mathrm{H}, \mathrm{d}, 7.5)$ \\
\hline \multicolumn{11}{|c|}{ Adenine } \\
\hline 11 & 141.0 & $8.25(1 \mathrm{H}, \mathrm{s})$ & 140.7 & $8.16(1 \mathrm{H}, \mathrm{s})$ & 140.5 & $8.10(1 \mathrm{H}, \mathrm{s})$ & 140.8 & $8.30(1 \mathrm{H}, \mathrm{s})$ & 141.0 & $8.26(1 \mathrm{H}, \mathrm{s})$ \\
\hline 12 & 119.5 & - & 119.5 & - & 119.2 & - & 119.4 & - & 119.3 & - \\
\hline 13 & 155.9 & - & 155.9 & - & 155.8 & - & 155.6 & - & 156.0 & - \\
\hline 14 & 153.2 & $8.24(1 \mathrm{H}, \mathrm{s})$ & 153.1 & $8.05(1 \mathrm{H}, \mathrm{s})$ & 153.0 & $8.08(1 \mathrm{H}, \mathrm{s})$ & 152.7 & $8.24(1 \mathrm{H}, \mathrm{s})$ & 153.5 & $8.11(1 \mathrm{H}, \mathrm{s})$ \\
\hline 15 & 149.2 & - & 149.0 & - & 148.5 & - & 150.6 & - & 149.2 & - \\
\hline \multicolumn{11}{|l|}{ Valine } \\
\hline $1^{\prime}$ & 172.2 & - & 178.4 & - & - & - & - & - & 172.0 & - \\
\hline $2^{\prime}$ & 60.2 & $4.16(1 \mathrm{H}, \mathrm{d}, 7.0)$ & 61.8 & $3.91(1 \mathrm{H}, \mathrm{d}, 7.0)$ & - & - & - & - & 60.5 & $4.05(1 \mathrm{H}, \mathrm{d}, 7.0)$ \\
\hline $3^{\prime}$ & 30.3 & $2.15(1 \mathrm{H}, \mathrm{m})$ & 30.2 & $1.95(1 \mathrm{H}, \mathrm{dqq}, 7.2,7.0)$ & - & - & - & - & 30.0 & $2.07(1 \mathrm{H}, \mathrm{m})$ \\
\hline $4^{\prime}$ & 18.6 & $0.96(3 \mathrm{H}, \mathrm{d}, 7.2)$ & 18.9 & $0.81(3 \mathrm{H}, \mathrm{d}, 7.2)$ & - & - & - & - & 17.7 & $0.88(3 \mathrm{H}, \mathrm{d}, 7.0)$ \\
\hline $5^{\prime}$ & 17.7 & $0.98(3 \mathrm{H}, \mathrm{d}, 7.2)$ & 17.8 & $0.78(3 \mathrm{H}, \mathrm{d}, 7.2)$ & - & - & - & - & 18.1 & $0.87(3 \mathrm{H}, \mathrm{d}, 7.0)$ \\
\hline \multicolumn{11}{|l|}{ Alanine } \\
\hline $1^{\prime \prime}$ & 181.3 & - & - & - & - & - & - & - & 179.2 & - \\
\hline $2^{\prime \prime}$ & 51.3 & $4.09(1 \mathrm{H}, \mathrm{q}, 7.1)$ & - & - & - & - & - & - & 50.5 & $4.01(1 \mathrm{H}, \mathrm{q}, 7.2)$ \\
\hline $3^{\prime \prime}$ & 17.9 & $1.31(3 \mathrm{H}, \mathrm{d}, 7.1)$ & - & - & - & - & - & - & 17.5 & $1.22(3 \mathrm{H}, \mathrm{d}, 7.2)$ \\
\hline
\end{tabular}




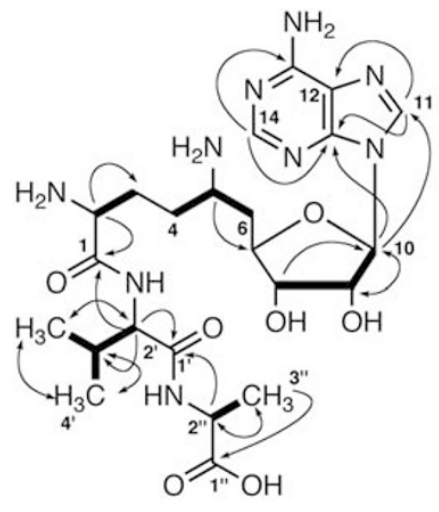

Sinefungin VA (1)

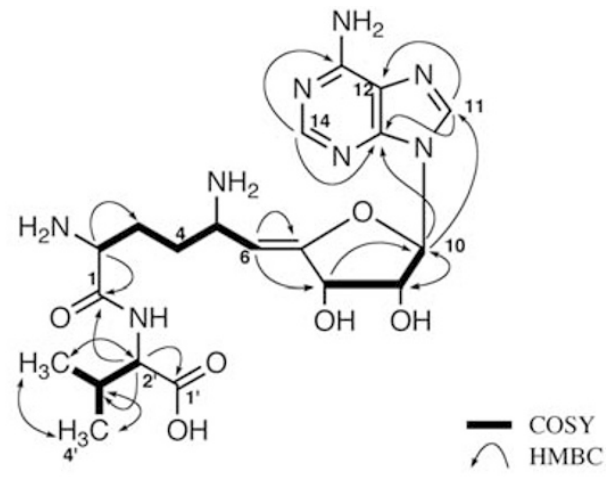

Dehydrosinefungin V (2)

Figure 4 COSY and HMBC studies of sinefungin VA (1) and dehydrosinefungin V (2).

Table 3 Antitrypanosomal activity and cytotoxicity of sinefungin analogs

\begin{tabular}{|c|c|c|c|}
\hline \multirow[b]{3}{*}{ Compound } & \multicolumn{2}{|l|}{$I_{50}\left(\mu g \mathrm{~m}^{-1}\right)$} & \multirow{3}{*}{$\begin{array}{c}\text { Selectivity index } \\
\text { MRC-5/T. b. b. }\end{array}$} \\
\hline & Antitrypanosomal activity & Cytotoxicity & \\
\hline & T. b. b. GUTat 3.1 & $M R C-5$ & \\
\hline Sinefungin VA (1) & 0.0026 & $>5$ & $>1923$ \\
\hline Dehydrosinefungin V (2) & 0.147 & 7.96 & 54 \\
\hline Sinefungin (3) & 0.00021 & 79 & 376000 \\
\hline Dehydrosinefungin (4) & 0.0587 & 2.10 & 35 \\
\hline KSA-9342 (5) & 0.186 & 3.91 & 21 \\
\hline Suramin ${ }^{a}$ & 1.58 & $>100$ & $>63$ \\
\hline
\end{tabular}

Abbreviations: $\mathrm{IC}_{50}$, inhibitory constant 50; T.b.b., Trypanosoma brucei brucei.

aSuramin is a drug used to treat Human African Trypanosomiasis.

\section{characteristic}

UV spectrum and fragment ion $(m / z 135)$ in FAB mass spectrum indicated the presence of an adenine moiety. Moreover, the spin systems from $\mathrm{H}-2$ to $\mathrm{H}-6$ and from $\mathrm{H}-8$ to $\mathrm{H}-10$, deduced by the ${ }^{1} \mathrm{H}-{ }^{1} \mathrm{H}$ COSY, and the correlations from $\mathrm{H}-2$ to $\mathrm{C}-1$ and $\mathrm{C}-3$, from $\mathrm{H}-6$ to $\mathrm{C}-7$ and $\mathrm{C}-8$, from $\mathrm{H}-8$ to $\mathrm{C}-10$ and from $\mathrm{H}-10$ to $\mathrm{C}-11$ and $\mathrm{C}-15$ of the adenine moiety in the HMBC spectra, revealed that 2 was a dehydrosinefungin analog (Figure 4). This was confirmed by comparison with the NMR spectra of dehydrosinefungin (Table 2). The spin systems from $\mathrm{H}-2^{\prime}$ to $\mathrm{H}_{3}-5^{\prime}$ by the COSY and the correlations from $\mathrm{H}-2^{\prime}$ to $\mathrm{C}-1^{\prime}$ in the $\mathrm{HMBC}$ spectra indicated the presence of a valyl moiety. The correlations from $\mathrm{H}-2^{\prime}$ to $\mathrm{C}-1$ in $\mathrm{HMBC}$ revealed the C-1 of dehydrosinefungin was attached to the amino group of the valyl moiety to form an amide bond. The absolute configuration of the valine residue was determined to be the L-form by HPLC analysis of the hydrolysates of $\mathbf{2}$ using a chiral column. The structure of $\mathbf{2}$ is shown in Figure 1, and the compound was designated as dehydrosinefungin $\mathrm{V}$.

\section{Biological activities}

As shown in Table 3, sinefungin VA (1) showed potent activity against Trypanosoma brucei brucei GUTat 3.1 strain with an $\mathrm{IC}_{50}$ value of $2.60 \times 10^{-3} \mu \mathrm{g} \mathrm{ml}^{-1}$, which was 10 -fold less than that of sinefungin ( $\mathrm{IC}_{50}$ value of $2.10 \times 10^{-4} \mu \mathrm{g} \mathrm{ml}^{-1}$ ) but approximately 600 -fold higher than that of the commonly used therapeutic drug, suramin.
However, 1 exhibited significantly less cytotoxicity against MRC-5 cells than sinefungin. Dehydrosinefungin V (2) showed moderate antitrypanosomal activity with $\mathrm{IC}_{50}$ values of $0.14 \mu \mathrm{g} \mathrm{ml}^{-1}$, which was similar to that of dehydrosinefungin (4) and KSA-9342 (5). A selectivity index (see Table 3), created to allow direct comparisons of effectiveness and cytotoxicity, indicated that sinefungin VA was almost 200 -fold less potent than sinefungin but that, significantly, it was some 30 -fold better than suramin.

\section{DISCUSSION}

Sinefungin and its analog, dehydrosinefungin, were isolated from a culture broth of Streptomyces griseolus and found to have antifungal and antitrypanosomal properties. ${ }^{4,5}$ Sinefungin is a nucleoside antibiotic containing an ornithine residue linked by a $\mathrm{C}-\mathrm{C}$ bond to the $5^{\prime}$ carbon of adenosine. The biosynthetic precursors of sinefungin were reported as being $\mathrm{L}$-arginine and ATP, using incorporation studies as well as HPLC analysis, ${ }^{7}$ although the details remain unclear. The isolation of sinefungin and its various analogs from the same culture broth in this study might provide a clue to help solve their biosynthesis pathway. Sinefungin is a structural analog of $S$-adenosylmethionine, a molecule that has an important role in the biosynthesis of polyamines and in transmethylations of proteins and lipids. Sinefungin and dehydrosinefungin are very potent inhibitors of $S$-adenosylmethionine-dependent transmethylations. ${ }^{8}$ Sinefungin was also reported to exhibit strong antiviral, antileishmanial and antitumor activity. ${ }^{8-10}$ In our study, compounds having a single bond between C-6 and C-7 of adenosine (sinefungin and sinefungin VA) showed potent antitrypanosomal activity as compared with compounds having a double bond (dehydrosinefungin, dehydrosinefungin $\mathrm{V}$ and KSA-9342). Many biological activities of sinefungin are believed to be related to the inhibition of $S$-adenosylmethionine-dependent methyltransferase enzymes. ${ }^{11-16}$

When administered intraperitoneally, sinefungin cures mice infected with T. brucei brucei, Trypanosoma congolense and Trypanosoma vivax. ${ }^{17,18}$ It was well tolerated in mice, and when the dose per injection was $0.05-5 \mathrm{mg} \mathrm{kg}^{-1}$, sinefungin was highly effective against African trypanosomes. Sinefungin and dehydrosinefungin were also leishmanicidal at concentrations ranging from 0.13 to $2.6 \mu \mathrm{M}$ in vitro. ${ }^{9}$ Our data confirm that sinefungin is both a potent antitrypanosomal and that it has a moderate cytotoxic effect against MRC-5 cells. Hitherto, sinefungin has not been developed because of its serious side effects (nephrotoxicity at subcurative levels in goats and dogs and toxicity for bone marrow cells). ${ }^{19,20}$ However, synthetic studies for 
some analogs have been reported to improve the therapeutic index. ${ }^{21,22}$ Our results indicate that sinefungin VA retains potent antitrypanosomal properties but with a greatly reduced cytotoxicity, significantly outperforming suramin, indicating that it could be a promising candidate for development into a novel new antitrypanosomal drug.

\section{METHODS}

\section{Taxonomic studies}

We observed cultural and physiological characteristics of strain K05-0178 grown on yeast extract-malt extract agar, oatmeal agar and inorganic saltsstarch agar, after incubation for 2 weeks at $27^{\circ} \mathrm{C}$. The morphological properties were observed with a scanning electron microscope (model JSM-5600, JEOL, Akishima, Japan) after cultivation on $1 / 10$ V8 juice agar at $27^{\circ} \mathrm{C}$ for 18 days. Isomers of diaminopimelic acid in whole-cell hydrolysates were determined by TLC, following the standard methods of Becker et al. ${ }^{23}$ and Hasegawa et al..$^{24}$ $16 \mathrm{~S}$ rDNA was amplified by PCR and sequenced directly on an ABI model 377A automatic DNA sequencer using a PRISM Ready Reaction Dye Primer Cycle Sequencing Kit (Applied Biosystems, Carlsbad, CA, USA).

\section{Fermentation}

The strain K05-0178 was grown and maintained on agar slants consisting of $1.0 \%$ starch, $0.3 \% \mathrm{NZ}$ amine, $0.1 \%$ yeast extract, $0.1 \%$ meat extract, $1.2 \%$ agar and $0.3 \% \mathrm{CaCO}_{3}$. A loop of spores of strain $\mathrm{K} 05-0178$ was inoculated into $100 \mathrm{ml}$ of seed medium, consisting of $2.4 \%$ starch, $0.1 \%$ glucose, $0.3 \%$ peptone, $0.3 \%$ meat extract, $0.5 \%$ yeast extract and $0.4 \% \mathrm{CaCO}_{3}$ (adjusted to $\mathrm{pH} 7.0$ before sterilization) in a 500-ml Erlenmeyer flask. The flask was incubated on a rotary shaker (210 r.p.m.) at $27^{\circ} \mathrm{C}$ for 3 days. A $1 \mathrm{ml}$ portion of the seed culture was transferred to 500-ml Erlenmeyer flasks (total 100) containing $100 \mathrm{ml}$ of production medium, consisting of $0.5 \%$ glucose, $0.5 \%$ corn steep powder, $1.0 \%$ oat meal, $1.0 \%$ Pharmamedia (Traders Protein, Lubbock, TX, USA), $0.5 \% \mathrm{~K}_{2} \mathrm{HPO}_{4}, 0.5 \% \mathrm{MgSO}_{4} \cdot 7 \mathrm{H}_{2} \mathrm{O}, 5.0 \times 10^{-4} \% \mathrm{FeSO}_{4} \cdot 7 \mathrm{H}_{2} \mathrm{O}, 5.0 \times 10^{-4} \%$

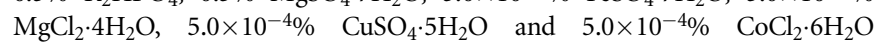
(adjusted to $\mathrm{pH} 7.0$ before sterilization) and fermentation was carried out on a rotary shaker (210 r.p.m.) at $27^{\circ} \mathrm{C}$ for 6 days.

\section{General experiments}

NMR spectra were measured using a Varian XL-400 spectrometer or a Varian Inova 600 spectrometer (Varian, Palo Alto, CA, USA), with ${ }^{1} \mathrm{H}$ NMR at 400 or $600 \mathrm{MHz}$ and ${ }^{13} \mathrm{C}$ NMR at 100 or $150 \mathrm{MHz}$ in $\mathrm{D}_{2} \mathrm{O}$. The chemical shifts are expressed in p.p.m. and are referenced to HDO (4.76 p.p.m.) in the ${ }^{1} \mathrm{H}$ NMR spectra and the end of both fields (0, 200 p.p.m.) in the ${ }^{13} \mathrm{C}$ NMR spectra. FAB-MS spectra were measured on a JEOL JMS AX-505 HA mass spectrometer. IR spectra $(\mathrm{KBr})$ were taken on a Horiba FT-210 Fourier (Horiba, Kyoto, Japan) transform infrared spectrometer. UV spectra were measured with a Beckman DU640 spectrophotometer (Beckman, Fullerton, CA, USA). Optical rotation was measured on a JASCO model DIP-181 polarimeter (JASCO, Hachioji, Japan).

\section{Amino acid analysis}

Each of 1-3 $(100 \mu \mathrm{g})$ was completely hydrolyzed in a gas phase of $6 \mathrm{M} \mathrm{HCl}$ $(100 \mu \mathrm{l})$ at $110^{\circ} \mathrm{C}$ for $18 \mathrm{~h}$ in a reaction vial in which air was replaced by $\mathrm{N}_{2}$ gas, using the Pico-Tag work station (Waters). For elucidation of the absolute configuration of amino acids, the hydrolysates were dissolved in distilled water and subjected to HPLC analysis (Column, Sumichiral OA-5000 (4.6 i.d. $\times 150 \mathrm{~mm}$, Sumika Chemical Analysis Service, Osaka, Japan); Mobile Phase, $2 \mathrm{~mm} \mathrm{CuSO}_{4}$; flow rate, $1.0 \mathrm{ml} \mathrm{min}^{-1}$; detection, $254 \mathrm{~nm}$; column temperature, $40^{\circ} \mathrm{C}$ ). Retention time (min): L-Ala 5.02, D-Ala 7.36, L-Val 12.2 and D-Val 22.1.

\section{Antitrypanosomal activity in vitro}

In vitro antitrypanosomal activities against $T$. brucei brucei strain GUTat 3.1 were measured, using the method described previously. ${ }^{25}$ In brief, the strain GUTat 3.1 was cultured in Iscove's modified Dulbecco's medium (IMDM) with various supplements and $10 \%$ heat-inactivated fetal bovine serum at $37^{\circ} \mathrm{C}$, under $5.0 \% \mathrm{CO}_{2} / 95 \%$ air. Subsequently, $95 \mu \mathrm{l}$ of the trypanosomes suspension $\left(2.0-2.5 \times 10^{4}\right.$ trypanosomes $\left.\mathrm{ml}^{-1}\right)$ was transferred in a 96-well microtiter plate and $5.0 \mu \mathrm{l}$ of a test compound solution (dissolved in 5.0\% DMSO) was added and incubated for $72 \mathrm{~h}$ at $37^{\circ} \mathrm{C}$ (long incubation-low inoculation test). After that, $10 \mu \mathrm{l}$ of the fluorescent dye alamer blue was added to each well. After incubation for $3-6 \mathrm{~h}$, the resulting solution was read at 528/20 nm excitation wavelengths and 590/ $30 \mathrm{~nm}$ emission wavelengths by an FLx800 fluorescence microplate reader (BioTek Instruments, Winooski, VT, USA). The $\mathrm{IC}_{50}$ values were determined using the fluorescent plate reader software (KC-4, BioTek). Successive subcultures were done in 24-well tissue culture plates under the same conditions.

\section{Cytotoxic activity in vitro}

Measurement of cytotoxic activity against human fetal lung fibroblast MRC-5 cells was carried out as described previously. ${ }^{26}$

\section{ACKNOWLEDGEMENTS}

This study was supported, in part, by funds from the Drugs for Neglected Diseases initiative, Quality Assurance Framework of Higher Education from the Ministry of Education, Culture, Sports, Science and Technology in Japan, and All Kitasato Project Study. We are grateful to Ms Hitomi Sekiguchi and $\mathrm{Mr}$ Toshiaki Furusawa for their technical assistance, Dr Hiroshi Honma and Dr Masae Sekine, School of Pharmacy, Kitasato University for amino acid analysis, and Ms Akiko Nakagawa, Dr Kenichiro Nagai and Ms Noriko Sato, School of Pharmacy, Kitasato University for measurements of mass and NMR spectra.

1 World Health Organization. African trypanosomiasis (sleeping sickness). Fact sheet No. 259 (2006).

2 Williams, S. T., Goodfellow, M. \& Alderson, G. Genus Streptomyces Waksman and Henrici 1943. in Bergey's Manual of Systematic Bacteriology, Vol. 4 (ed. Williams, S. T. et al.) 2452-2492 (Williams \& Wilkins, 1989).

3 Witt, D. \& Stackebrandt, E. Unification of the genera Streptoverticillium and Streptomyces, and amendation of Streptomyces Waksman and Henrici 1943, 339AL. Syst. Appl. Microbiol. 13, 361-371 (1990).

4 Hamill, R. L. \& Hoehn, M. M. A9145, a new adenine-containing antifungal antibiotic. I. Discovery and isolation. J. Antibiot. 26, 463-465 (1973).

5 Berry, D. R. \& Abbott, B. J. Incorporation of carbon-14-labeled compounds into sinefungin (A9145), a nucleoside antifungal antibiotic. J. Antibiot. 31, 185-191 (1978).

6 Yamashita, K., Suzuki, A., Isogai, A., Sawai, N. \& Kobayashi, R. Fungicidal antibiotic KSA-9342 and its manufacture with Streptoverticillium. Japan Patent Application 63-297398, 5 December (1988).

7 Malina, H., Tempete, C. \& Robert-Gero, M. Biosynthesis of sinefungin by cell-free extract of Streptomyces incarnates NRRL 8089. J. Antibiot. 40, 505-511 (1987).

8 Vedel, M., Lawrence, F., Robert-Gero, M. \& Lederer, E. The antifungal antibiotic sinefungin as a very active inhibitor of methyltransferases and of the transformation of chick embryo fibroblasts by Rous sarcoma virus. Biochem. Biophys. Res. Commun. 85, 371-376 (1978).

9 Paolantonacci, P., Lawrence, F., Lederer, F. \& Robert-Gero, M. Differential effect of sinefungin and its analogs on the multiplication of three Leishmania species. Antimicrob. Agents Chemother. 28, 528-531 (1985).

10 Suhadolnik, R. J. Nucleosides as Biological Probes 19-23 (Wiley, New York, 1979).

11 Pugh, C. S. \& Borchardt, R. T. Effects of S-adenosylhomocysteine analogues on vaccinia viral messenger ribonucleic acid synthesis and methylation. Biochemistry 21, 1535-1541 (1982).

12 Fuller, R. W. \& Nagarajan, R. Inhibition of methyltransferases by some new analogs of S-adenosylhomocysteine. Biochem. Pharmacol. 27, 1981-1983 (1978).

13 MaCammon, M. T. \& Parks, L. W. Inhibition of sterol transmethylation by S-adenosylhomocysteine analogs. J. Bacteriol. 145, 106-112 (1981).

14 Bacchi, C. J. et al. Fate of soluble methionine in African trypanosomes: effects of metabolic inhibitors. Biochem. J. 309, 737-743 (1995).

15 Pugh, C. S. G., Borchardt, R. T. \& Stone, H. O. Sinefungin, a potent inhibitor of virion mRNA(guanine-7-)-methyltransferase, mRNA(nucleoside-2'-)-methyltransferase, and viral multiplication. J. Biol. Chem. 253, 4075-4077 (1978).

16 Ghosh, A. K. \& Liu, W. Total synthesis of (+)-sinefungin. J. Org. Chem. 61, 6175-6182 (1996).

17 Dube, D. K., Mpimbaza, G., Allison, A. C., Lederer, E. \& Rovis, L. Antitrypanosomal activity of sinefungin. Am. J. Trop. Med. Hyg. 32, 31-33 (1983).

18 Zweygarth, E. \& Rottcher, D. Efficacy of experimental trypanocidal compounds against a multiple drug-resistant Trypanosoma brucei brucei stock in mice. Parasitol. Res. 75, 178-182 (1989).

19 Zweygarth, E., Schillinger, D., Kaufman, W. \& Rottcher, D. Evaluation of sinefungin for the treatment of Trypanosoma (Nannomonas) congolense infections in goats. Trop. Med. Parasitol. 37, 255-257 (1986).

20 Barton, D. H. et al. Total synthesis of uracil analogues of sinefungin. J. Med. Chem. 35, 63-67 (1992). 
21 Lyga, J. W. \& Secrist, J. A. III. Synthesis of chain-extended and C-6' functionalized precursors of the nucleoside antibiotic sinefungin. J. Org. Chem. 48, 1982-1988 (1983).

22 Blanchard, P. et al. Synthesis and biological activity of sinefungin analogues. J. Med. Chem. 34, 2798-2803 (1991).

23 Becker, B., Lechevalier, M. P. \& Lechevalier, H. A. Chemical composition of cell-wall preparation from strains of various form-genera of aerobic actinomycetes. Appl. Microbiol. 13, 236-243 (1965).
24 Hasegawa, T., Takizawa, M. \& Tanida, S. A rapid analysis for chemical grouping of aerobic actinomycetes. J. Gen. Appl. Microbiol. 29, 319-322 (1983).

25 Otoguro, K. et al. Selective and potent in vitro antitrypanosomal activities of 10 microbial metabolites. J. Antibiot. 61, 372-378 (2008).

26 Otoguro, K. et al. Potent antimalarial activities of polyether antibiotic, X-206. J. Antibiot. 54, 658-663 (2001). 